\title{
Influence of Thermal Conductivity on the Thermal Behavior of Intermediate-Temperature Solid Oxide Fuel Cells
}

\author{
Nurul Ashikin Mohd Nazrul Aman ${ }^{1}$, Andanastuti Muchtar ${ }^{1,2 *}$, Masli Irwan Rosli ${ }^{3}$, \\ Nurul Akidah Baharuddin ${ }^{1}$, Mahendra Rao Somalu ${ }^{1}$, and Noor Shieela Kalib ${ }^{1,4}$ \\ ${ }^{1}$ Fuel Cell Institute, Universiti Kebangsaan Malaysia, 43600 UKM Bangi, Selangor, Malaysia \\ ${ }^{2}$ Centre for Materials Engineering and Smart Manufacturing (MERCU), Faculty of Engineering and Built Environment, \\ Universiti Kebangsaan Malaysia, 43600 UKM Bangi, Selangor, Malaysia \\ ${ }^{3}$ Centrefor Sustainable Process Technology (CESPRO), Faculty of Engineering and Built Environment, Universiti Kebangsaan \\ Malaysia, 43600, UKM, Bangi, Selangor, Malaysia \\ ${ }^{4}$ School of Engineering and Physical Sciences, Heriot-Watt University Malaysia, Precinct 5, 62200 Putrajaya, Malaysia
}

\begin{abstract}
Solid oxide fuel cells (SOFCs) are among one of the promising technologies for efficient and clean energy. SOFCs offer several advantages over other types of fuel cells under relatively high temperatures $\left(600^{\circ} \mathrm{C}\right.$ to $\left.800^{\circ} \mathrm{C}\right)$. However, the thermal behavior of SOFC stacks at high operating temperatures is a serious issue in SOFC development because it can be associated with detrimental thermal stresses on the life span of the stacks. The thermal behavior of SOFC stacks can be influenced by operating or material properties. Therefore, this work aims to investigate the effects of the thermal conductivity of each component (anode, cathode, and electrolyte) on the thermal behavior of samarium-doped ceria-based SOFCs at intermediate temperatures. Computational fluid dynamics is used to simulate SOFC operation at $600^{\circ} \mathrm{C}$. The temperature distributions and gradients of a single cell at $0.7 \mathrm{~V}$ under different thermal conductivity values are analyzed and discussed to determine their relationship. Simulations reveal that the influence of thermal conductivity is more remarkable for the anode and electrolyte than for the cathode. Increasing the thermal conductivity of the anode by $50 \%$ results in a $23 \%$ drop in the maximum thermal gradients. The results for the electrolyte are subtle, with a $\sim 67 \%$ reduction in thermal conductivity that only results in an $8 \%$ reduction in the maximum temperature gradient. The effect of thermal conductivity on temperature gradient is important because it can be used to predict thermal stress generation.
\end{abstract}

Keywords : Computational Fluid Dynamics, Modeling, SOFC, Thermal Conductivity, Thermal Behavior

Received : 30 May 2019, Accepted : 14 October 2019

\section{Introduction}

Solid oxide fuel cells (SOFCs) are among one of the most efficient energy conversion tools with efficiencies of up to $65 \%$ [1]. This technology can serve as a stationary power generator to replace traditional internal combustion. SOFCs exhibit advantages such as fuel flexibility, low pollution, and potential for cogeneration with other industries, under typically high temperatures $\left(600^{\circ} \mathrm{C}\right.$ to $\left.1000^{\circ} \mathrm{C}\right)$ [2]. However, high

*E-mail address: muchtar@ukm.edu.my

DOI: https://doi.org/10.33961/jecst.2019.00276

This is an open-access article distributed under the terms of the Creative Commons Attribution Non-Commercial License (http://creativecommons.org/licenses/by-nc/4.0)
which permits unrestricted non-commercial use, distribution, and reproduction in any which permits unrestricted non-commercial use, distri
medium, provided the original work is properly cited. operating temperatures lead to difficulties in selecting materials. Moreover, decreased durability associated with thermal stress generation during prolonged operations is unavoidable and has become a hurdle in the commercialization of SOFCs [3]. To overcome these issues, scholars have focused on developing SOFCs with high performance at operating temperatures lower than $800^{\circ} \mathrm{C}[4,5]$. Although numerous researchers have focused on the electrochemical performance of SOFCs, the thermal performance of these tools at intermediate temperatures requires equal attention. The durability issue can be addressed if the source can be defined and managed properly.

In SOFCs, the durability issue is as important as electrochemical performance because it affects the life span and failure of SOFC stacks. One of the 
major sources that contribute to the reduced thermal durability of SOFCs is thermal stress generation within stacks during start-up, operation, and shut down [6]. Thermal stresses can be influenced by temperature gradients and components' thermal expansion coefficients $[7,8]$. An increase in temperature gradients causes thermal stress to rise [9]. Localized hot spots where the highest temperature gradients occur bear the highest thermal stress because materials expand greatly at these points; mismatch among thermal expansion coefficients of component also worsens stress generation given that it may result in the curling of the components [10].

Temperature gradients can be managed through several methods, such as the cooling effect by inlet gasses or materials' thermal conductivities. The cooling effect resulting from the variation in air flow rates reduces the temperature difference within a stack
$[11,12]$. However, the discussion on the effects of materials' thermal conductivities on the temperature behavior of SOFCs remains limited [13,14]. Researchers can predict the temperature distributions and gradients within cells and plan for effective heat management strategies by understanding the effects of materials' thermal conductivities. Therefore, the current study aims to determine and discuss the effects of the thermal conductivities of the anode, cathode, and electrolyte on the temperature distribution within a single samarium-doped ceria (SDC)based SOFC stack. The SDC-based SOFC is selected in this study due to the performance of SDC at intermediate temperatures $\left(600^{\circ} \mathrm{C}\right.$ to $\left.800^{\circ} \mathrm{C}\right)$, which is better than that of the traditional yttria stabilized zirconia (YSZ) [12]. The thermal behavior of the SOFC is investigated at $600^{\circ} \mathrm{C}$ because it is the lower limit of intermediate temperatures.

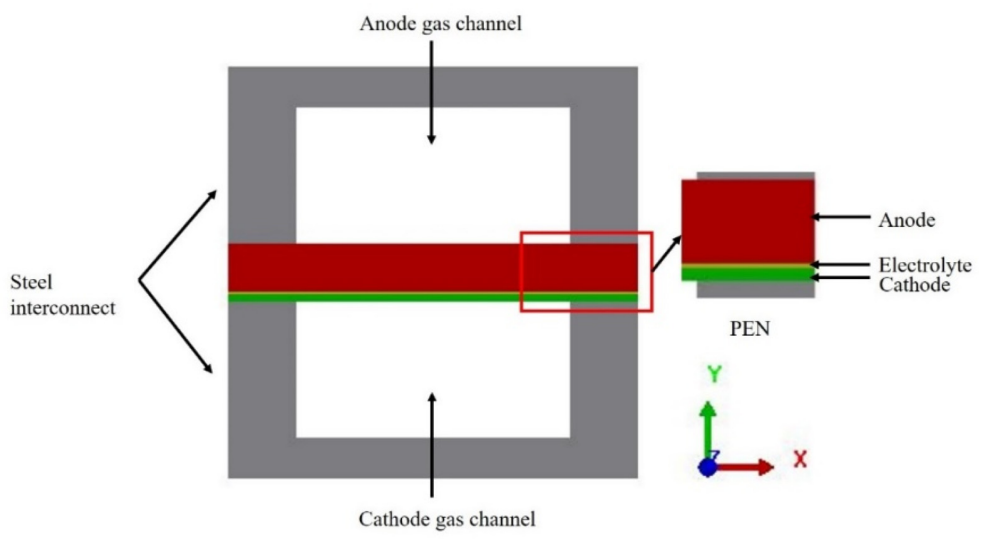

(a)

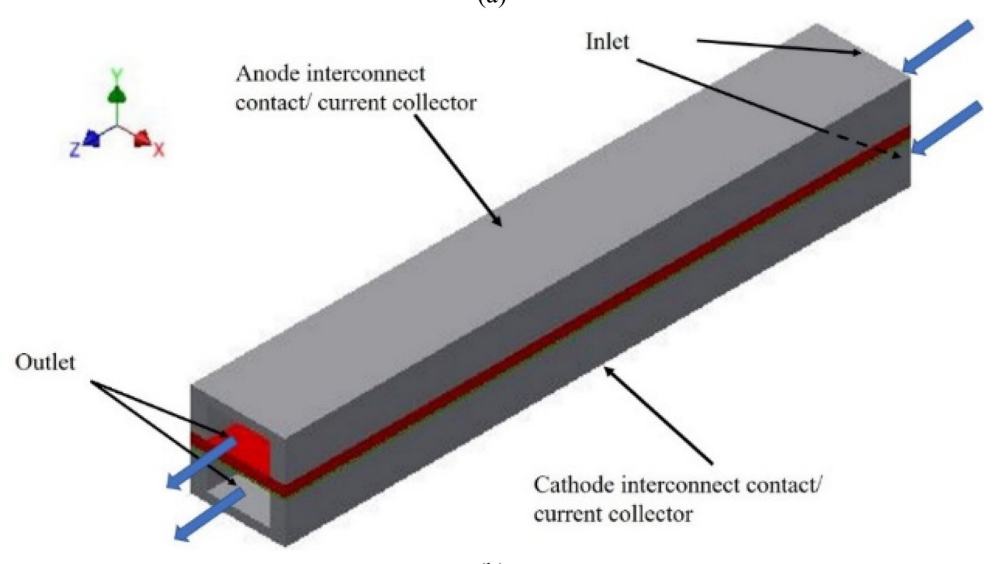

(b)

Fig. 1. Schematic of SOFC stack model: (a) front view and (b) isometric view. 
Table 1. Details of SOFC stack model used in this study

\begin{tabular}{ccccc}
\hline \hline Component & Material & Length $(\mathrm{mm})$ & Width $(\mathrm{mm})$ & Thickness/height $(\mathrm{mm})$ \\
\hline Electrolyte & SDC & 40 & 2 & 0.02 \\
Anode & Ni-SDC & 40 & 2 & 0.35 \\
Cathode & LSCF-SDC & 40 & 2 & 0.02 \\
Interconnect & Stainless steel & 40 & 3 & 1.3 \\
Gas channel & & 40 & 2 & 1 \\
\hline
\end{tabular}

Table 2. Physical properties of anode, cathode, and electrolyte

\begin{tabular}{|c|c|c|c|c|}
\hline Parameter & Unit & Anode (Ni-SDC) & Electrolyte (SDC) & Cathode (LSCF) \\
\hline Porosity, $\varepsilon$ & $\%$ & 30 & $1 \times 10^{-20}$ & 30 \\
\hline Permeability, $\beta$ & $\mathrm{m}^{2}$ & $1 \times 10^{-12}$ & $1 \times 10^{-18}$ & $1 \times 10^{-12}$ \\
\hline Tortuosity factor, $\tau$ & & 3 & 3 & 3 \\
\hline $\begin{array}{l}\text { Ratio of active surface } \\
\text { area to volume, } S / V\end{array}$ & $\mathrm{~m}^{2} / \mathrm{m}^{3}$ & $3 \times 10^{5}$ & - & $3 \times 10^{5}$ \\
\hline Electrical conductivity, $\sigma$ & $\Omega \mathrm{m}^{-1}$ & $80000[15]$ & & $8400[16]$ \\
\hline Pore size & $\mathrm{m}$ & $1 \times 10^{-6}$ & $1 \times 10^{-6}$ & $1 \times 10^{-6}$ \\
\hline
\end{tabular}

Table 3. Parameters for modeling the reactions

\begin{tabular}{ccc}
\hline \hline Electrode & Reactions & Reference exchange current density, $I_{0}\left(\mathrm{~A} / \mathrm{m}^{3}\right)$ \\
\hline Anode & $2 \mathrm{H}_{2}+\mathrm{O}^{2-} \rightarrow 2 \mathrm{H}_{2} \mathrm{O}+2 \mathrm{e}$ & $2.191 \times 10^{9}[15,17]$ \\
Cathode & $\mathrm{O}_{2}+2 \mathrm{e} \rightarrow \mathrm{O}^{2-}$ & $610.834 \times 10^{6}[4,17]$ \\
\hline
\end{tabular}

\section{Experimantal}

\subsection{Cell geometry}

Commercial computational fluid dynamics (CFD) software package CFD-ACE $+{ }^{\mathrm{TM}} \mathrm{v} 2014.0$ is used to model and simulate the operation of the SOFC stack at $600^{\circ} \mathrm{C}$. The three-dimensional model is built on the basis of the SOFC stack developed by Cui et al. (2010), as shown in Fig. 1. The SOFC model consists of four main components, namely, electrolyte, anode, cathode, and a pair of interconnects at the anode and cathode sides. The work of Cui et al. (2010) is used as a reference due to the similarities of the SDC-based materials studied and their use of simulations to support their findings. Therefore, some of the parameters used in the current study are obtained from their work. The components of the electrolyte, anode, cathode, and interconnects and their dimensions are listed in Table 1. The manipulated variable is the thermal conductivity of the anode, cathode, and electrolyte. Other physical properties of the three components are fixed throughout the experiment (Table 2).

\subsection{Chemical reactions}

In an SOFC, fuel and air are supplied to the anode and cathode for electrochemical reactions to occur. The chemical reactions are modeled as a surface reaction with oxygen reduction at the cathode and hydrogen oxidation at the anode. The other values used to model the reactions are listed in Table 3. The values for the reference exchange current densities are based on several published works, including that of Cui et al. (2010), to ensure the suitability of the values to the developed model.

\subsection{Boundary conditions}

The inlet of the anode channel is supplied with humidified hydrogen $\left(97 \% \mathrm{H}_{2}+3 \% \mathrm{H}_{2} \mathrm{O}\right)$, and the cathode channel is supplied with air $\left(21 \% \mathrm{O}_{2}+79 \% \mathrm{~N}_{2}\right)$ in the same direction [18]. The simulation is conducted at $600^{\circ} \mathrm{C}$ and $0.7 \mathrm{~V}$. The operating voltage is set to $0.7 \mathrm{~V}$ due to the nature of SOFCs, which are usually operated between 0.6 and $0.7 \mathrm{~V}$ [19]. The humidified hydrogen is supplied at $1 \times 10^{-8} \mathrm{~kg} / \mathrm{s}$, and that of air is supplied at $8 \times 10^{-6} \mathrm{~kg} / \mathrm{s}$. 
The temperatures of both gases at the inlets are fixed at $600^{\circ} \mathrm{C}$. The pressure is fixed at $1 \mathrm{~atm}$ at both outlets. The anode and cathode contact (located on the interconnects' surfaces) is treated as an isothermal wall with a temperature of $600^{\circ} \mathrm{C}$, and the other walls are treated as an adiabatic wall to focus on the impact of heat generation from the electrochemical reactions on the thermal behavior of the model [9].

\subsection{Model validation}

A grid independent test is carried out by changing the mesh element size at the anode-electrolyte-cathode structure and along the model length. Four models with 32 000, 48 800, 62 400, and 78000 mesh elements are simulated and compared in terms of their output current values and profile temperatures. The mesh elements exert an insignificant effect on output current values. However, the temperature profiles change significantly when the number of mesh elements increases. Grid independency is achieved at 62400 mesh elements as increasing mesh numbers beyond this value has an insignificant effect on the current output value and temperature profile. Therefore, the model with 62400 mesh elements is selected to be used throughout this study. The simulation is terminated when the residual for the numerical solutions decreases by at least four orders of magnitude for each computed variable [20]. Convergence is reached in approximately $8 \mathrm{~h}$ on an Intel $\AA$ Xeon ${ }^{\circledR} 4$ CPU with 16 GB RAM and 3.6 GHz.

For validation, the voltage-current density (IV) curve from the simulation data is compared with that reported by Cui et al. (2010) (experimental); in both studies, the SOFCs are based on SDC. To obtain the IV curve closest to the one from the study of Cui et al. (2010), the present work manipulates the Tafel constant $(\alpha)$, one of the parameters for electrochemical reaction. This value is usually set to 0.5 in SOFC simulations [21]. However, during validation, the pattern can be made closer to that in the literature by

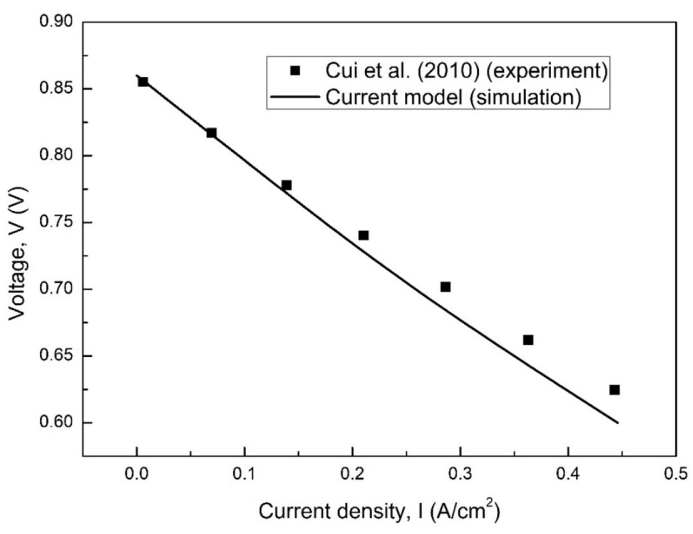

Fig. 2. Comparison between IV curves in this study and in literature.

changing the $\alpha$ value. Therefore, $\alpha$ is tested within 0.5 to 1 given that the suitable value for SOFC simulations typically ranges from 0 to 1 [22]. After varying the $\alpha$ value, the IV curve pattern that closely matches the IV curve from the literature is found at $\alpha=1$. Figure 2 shows the comparison of the simulated and experimental IV curves. The simulation results agree well with the experimental data reported by Cui et al. (2010) and present a relatively low average root mean square error of 0.014 , which indicates that the model is reliable to be used for the entire study.

\section{Results and Discussion}

Thermal conductivity is an important parameter in heat transfer because it affects temperature distributions and gradients. Each component (electrolyte, cathode, and anode) is simulated with different values to determine their significance to the thermal behavior of the model. The values represent the effects of the high, low, and original thermal conductivities of each component. The original value is the thermal conductivity obtained from the literature for

Table 4. Thermal conductivities used for simulations

\begin{tabular}{cccc}
\hline \hline \multirow{2}{*}{ Component } & $\begin{array}{c}\text { Thermal conductivity value from literature, } \\
k(\mathrm{~W} / \mathrm{m} . \mathrm{K})\end{array}$ & \multicolumn{2}{c}{ Tested thermal conductivity, $k(\mathrm{~W} / \mathrm{m} . \mathrm{K})$} \\
\cline { 3 - 4 } Electrolyte & $2.5[23]$ & Lower & Higher \\
Cathode & $3.5[24]$ & 2.5 & 3.5 \\
Anode & $12[25]$ & 6 & 4.5 \\
\hline
\end{tabular}


each component. The values of the thermal conductivity simulated are listed in Table 4.

Figs. 3, 4 and 5 show the temperature distributions along the model at different thermal conductivity values for the electrolyte, cathode, and anode, respectively. The temperature distribution pattern is nearly the same for all components. The temperature increases along the length of the model and reaches the maximum near the outlet. The increase in temperature is mainly due to heat generation during electrochemical reactions and conduction along the components. For the cathode and electrolyte, the variation in the temperature profiles is nearly unno- ticeable at different thermal conductivity levels. However, a different case is observed at varying thermal conductivity levels of the anode. Fig. 5 shows that the maximum temperature near the outlet increases with the increase in thermal conductivity. This finding is probably due to the fast heat transfer at high thermal conductivity [14]. The temperature gradients along the cell are determined to further understand the thermal behavior of the model and relate it to thermal stress.

Fig. 6 shows the temperature gradient along the single cell for different electrolyte, cathode, and anode thermal conductivities. For all values of ther-

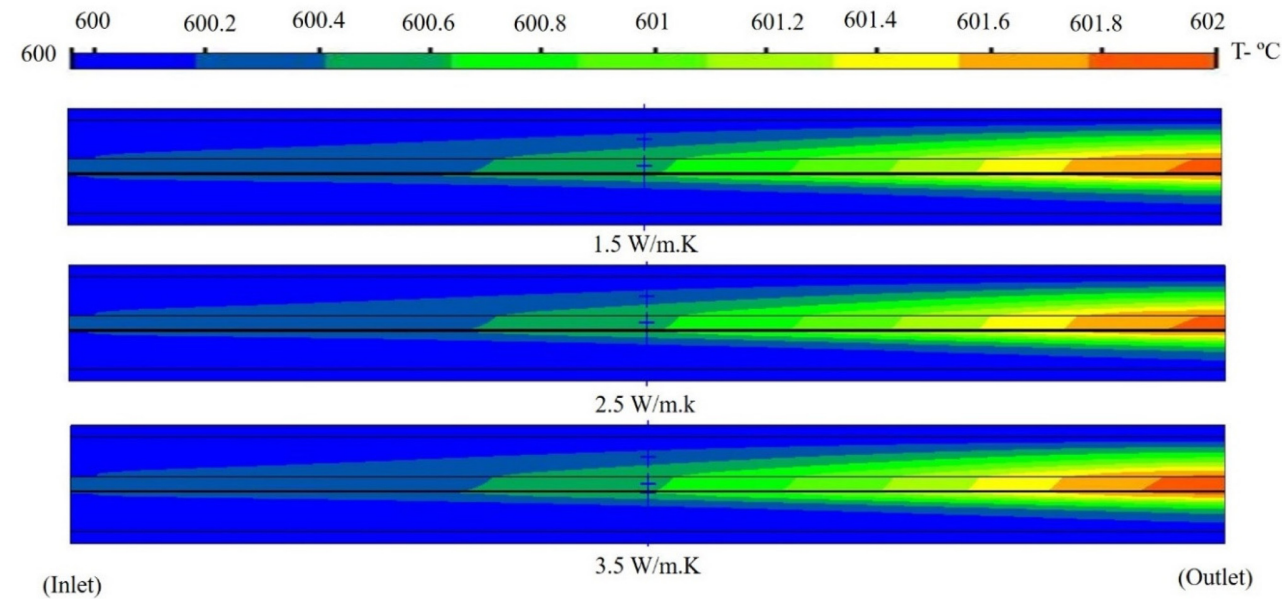

Fig. 3. Temperature profile along the model for different thermal conductivity values of the electrolyte.

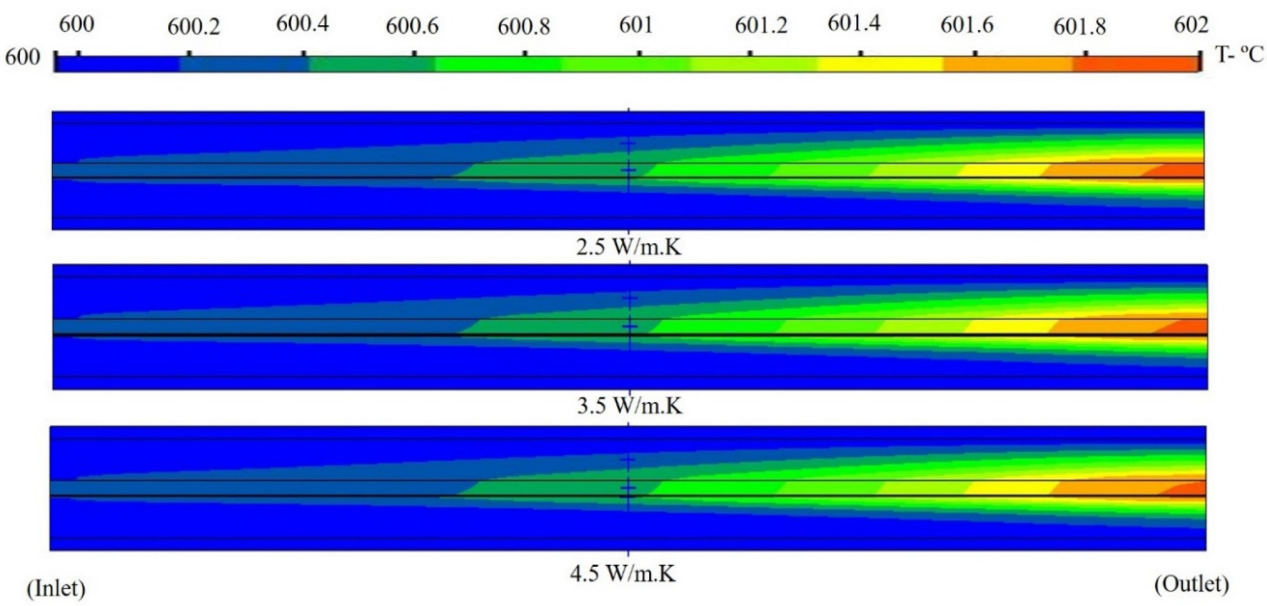

Fig. 4. Temperature profile along the model for different thermal conductivity values of the cathode. 


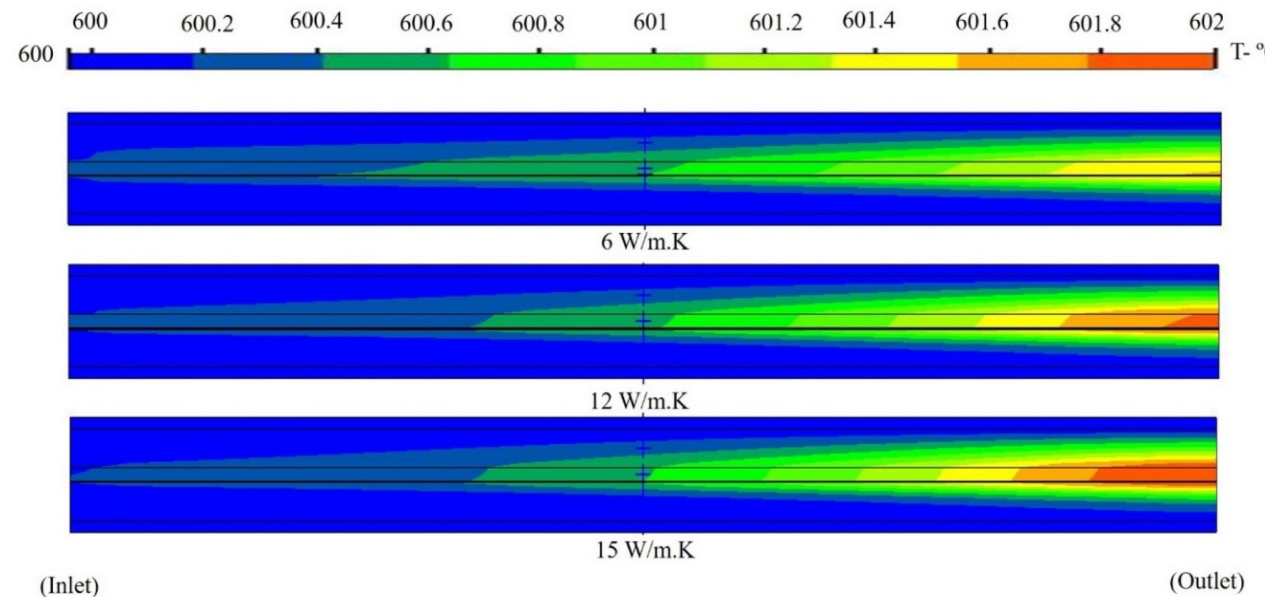

Fig. 5. Temperature profile along the model for different thermal conductivity values of the anode.

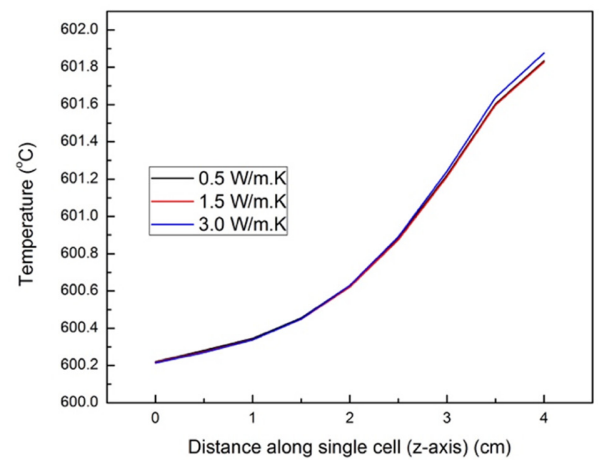

(a)

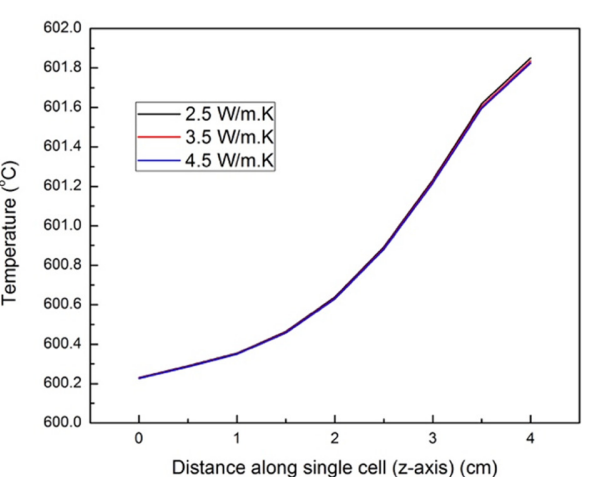

(b)

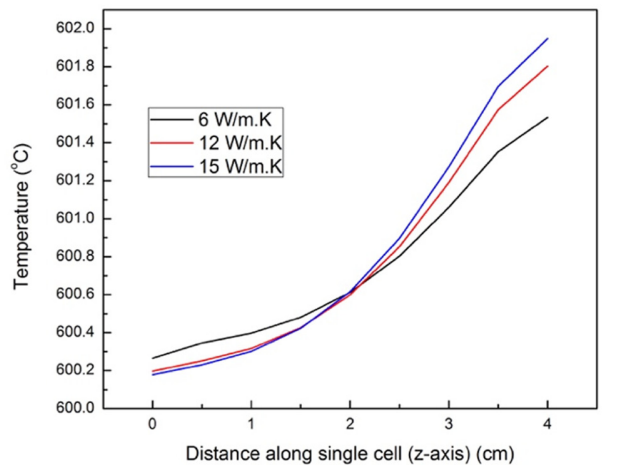

(c)

Fig. 6. Temperature gradients along the length of the model at different thermal conductivity levels: (a) electrolyte, (b) cathode, and (c) anode.

mal conductivities, the temperature gradient pattern can be divided into three parts. The first temperature gradient occurs near the inlet $(\mathrm{z}=0.0 \mathrm{~cm})$. The gradient is smaller than that in the middle part of the single 
cell because the electrochemical reactions just start and the flow is still developing. The second temperature gradient is at the middle of the single cell, where the temperature increases steadily and greatly compared with that in the first gradient. The increase in temperature along the model is due to the heat generated by the electrochemical reactions at the anodeelectrolyte interface [11]. In real applications, hydrogen oxidation at the anode-electrolyte interface is highly exothermic, whereas the oxygen reduction at the electrolyte-cathode interface is endothermic in nature [26]. The difference in heat generated and consumed in both reactions results in the large temperature gradient along the single cell. The third part was near the outlet $(\mathrm{z}=4.0 \mathrm{~cm})$ where the temperature gradient decreases as the flow approaches the outlet due to lower external temperature.

From the temperature gradients for each component, the effects of thermal conductivity on temperature gradient are more visible for the anode than for the electrolyte and cathode. The simulations show that the temperature gradient for the electrolyte decreases by $8.3 \%$ from $77.42 \mathrm{~K} / \mathrm{m}$ to $70.97 \mathrm{~K} / \mathrm{m}$ when the thermal conductivity decreases by $67 \%$ from $1.5 \mathrm{~W} / \mathrm{m} . \mathrm{K}$ to $0.5 \mathrm{~W} / \mathrm{m} . \mathrm{K}$; it does not change when the thermal conductivity further increases. For the anode, the temperature gradient decreases by $23 \%$ from $74.90 \mathrm{~K} / \mathrm{m}$ to $57.40 \mathrm{~K} / \mathrm{m}$ when the thermal conductivity decreases by $50 \%$ from $12 \mathrm{~W} / \mathrm{m} . \mathrm{K}$ to $6 \mathrm{~W} / \mathrm{m} . \mathrm{K}$; it increases by $11.5 \%$ from $74.90 \mathrm{~K} / \mathrm{m}$ to $82.60 \mathrm{~K} / \mathrm{m}$ when the thermal conductivity increases by $25 \%$ to $15 \mathrm{~W} / \mathrm{m} . \mathrm{K}$. The remarkable variation in temperature gradients for different thermal conductivity levels of the anode is probably due to its thick support structure relative to the thin electrolyte [27]. On the contrary, the thermal conductivity of the cathode does not exert a substantial effect on the temperature gradients probably due to the endothermic generation at the cathode. The anode has the largest temperature gradient and is thus more susceptible to thermal stress than the other components [27]. Therefore, producing anodes and electrolytes with the lowest thermal conductivities possible is important to avoid damage due to thermal stress $[7,28]$.

\section{Conclusions}

To determine the effects of the thermal conductivity of each component (electrolyte, anode, and cath- ode) on the temperature distributions of SOFCs, this study presents a CFD model of SDC-based SOFC. The simulation data are validated with experimental data from the literature to ensure the reliability of the predicted results. A good agreement is obtained between the simulation and experimental results. The effects of the thermal conductivity of each component are further simulated. The thermal conductivities of the anode and electrolyte influence the stack's temperature distribution particularly due to the exothermic reaction. The significance of thermal conductivity is greater for the anode because it has a thicker structure than the electrolyte. Meanwhile, the thermal conductivity of the cathode is insignificant in controlling the stack's temperature distribution. Overall, anodes and electrolytes with low thermal conductivities are preferred to control the temperature distributions and gradients within SOFC stacks.

\section{Acknowledgement}

The authors would like to thank the Ministry of Higher Education for their support through the research grant FRGS/1/2018/TK10/UKM/01/2.

\section{References}

[1] M. Anwar, A. Muchtar, and M. R. Somalu, Int. J. Appl. Eng. Res., 2016, 11(19), 973-4562.

[2] Z. Gao, L. V. Mogni, E. C. Miller, J. G. Railsback, and S. A. Barnett, Energy Environ. Sci., 2016, 9(5),16021644.

[3] L. S. Mahmud, A. Muchtar, and M. R. Somalu, Renew. Sustain. Energy Rev, 2017, 72, 105-116.

[4] S. A. Muhammed Ali, M. Anwar, N. F. Raduwan, A. Muchtar, and M. R. Somalu, J. Sol-Gel Sci. Technol., 2018, $86(2), 1-12$.

[5] N. A. Baharuddin, A. Muchtar, and D. Panuh, J. Kejuruter, 2018, SI 1(2), 1-8.

[6] M. Peksen, Prog. Energy Combust. Sci., 2015, 48, 1-20.

[7] N. Mahato, S. Sharma, A. K. Keshri, A. Simpson, A. Agarwal, and K. Balani, J. Mater. Met. Mater. Soc., 2013, 65(6), 749-762.

[8] N. S. Kalib, A. Muchtar, M. R. Somalu, A. K. A. Mohd Ihsan, and N. A. Mohd Nazrul Aman, J. Adv. Res. Fluid Mech. Therm. Sci., 2018, 50(2), 146-152.

[9] T. Choudhary and Sanjay, Int. J. Hydrogen Energy, 2016, 41(24), 10212-10227.

[10] M. Xu, T. Li, M. Yang, and M. Andersson, Sci. Bull., 2016, 61(17), 1333-1344.

[11] E. Guk, J. S. Kim, M. Ranaweera, V. Venkatesan, and L. Jackson, Appl. Energy, 2018, 230, 551-562.

[12] M. Andersson, J. Yuan, and B. Sundén, Int. J. Heat 
Mass Transf., 2012, 55(4), 773-788.

[13] G. Yang, D. Yue, H. Li, and X. Lv, International Conference on Advances in Energy Engineering, ICAEE 2010, 2010,(2), 325-328.

[14] A. Yahya, R. Rabhi, H. Dhahri, and K. Slimi, Powder Technol., 2018, 338, 402-415.

[15] C. Yang, J. G. Cheng, H. G. He, and J. F. Gao, Key Eng. Mater, 2010, 434-435(3), 731-734.

[16] S. A. Muhammed Ali, A. Muchtar, A. Bakar Sulong, N. Muhamad, and E. Herianto Majlan, Ceram. Int., 2013, 39(5), 5813-5820.

[17] D. Cui, Q. Liu, and F. Chen, J. Power Sources, 2010, 195(13), 4160-4167.

[18] D. Saebea, S. Authayanun, Y. Patcharavorachot, and A. Arpornwichanop, Chem. Eng. Trans., 2016, 52, 223-228.

[19] P. Aguiar, C. S. Adjiman, and N. P. Brandon, J. Power Sources, 2004, 138(1-2), 138, 120-136.

[20] P. A. Ramakrishna, S. Yang, and C. H. Sohn, J. Power
Sources, 2006, 158(1), 378-384.

[21] M. Navasa, J. Yuan, and B. Sunden, Appl. Energy, 2015, 137, 867-876.

[22] T. Suther, A. Fung, M. Koksal, and F. Zabihian, Sustainability, 2010, 2(11), 3549-3560.

[23] C. L. Wan, W. Pan, Z. X. Qu, and Y. X. Qin, Key Eng. Mater., 2007, 336-338, 1773-1775.

[24] Y.-C. Shin, S. Hashimoto, K. Yashiro, K. Amezawa, and T. Kawada, ECS Trans., 2016, 72(7), 105-110.

[25] K. Yuan, Y. Ji, and J. N. Chung, J. Power Sources, 2009, 194(2), 908-919.

[26] A. Amiri et al., Int. J. Hydrogen Energy, 2016, 41(4), 2919-2930.

[27] J. B. Robinson et al., J. Power Sources, 2015, 288, 473481.

[28] A. A. Kulikovsky, Int. J. Hydrogen Energy, 2010, 35(1), 308-312. 